\title{
COMPARISON OF MUSCLE STRENGTH IN MALE COMBAT SPORT ATHLETES
}

\author{
KRZYSZTOF BUŚKO \\ Kazimierz Wielki University in Bydgoszcz, Faculty of Physical Education, Health and Tourism, \\ Department of Anatomy and Biomechanics
}

\author{
Mailing address: Krzysztof Buśko, Institute of Sport - National Research Institute, Department of Biomechanics, \\ 2/16 Trylogii Street, 01-982 Warsaw, tel.: +48 22 5699951, fax: +48 22 8350977, e-mail: krzysztof.busko@insp.waw.pl
}

\begin{abstract}
Introduction. The aim of the study was to examine differences in muscle strength and topography between judoists, boxers, and taekwondo athletes. Material and methods. Thirteen judoists, 6 boxers, and 7 taekwondo athletes took part in the study. The maximal joint torque of the flexors and extensors of the elbow, shoulder, hip, knee, and trunk were measured under isometric conditions. Results. The absolute and relative joint torque was similar in the three groups except for the absolute strength of the right flexor of the shoulder between the boxers and the taekwondo athletes and judoists $(\mathrm{p}<0.01)$. The sums of the relative joint torque and topography of the joint torque of the right and left upper extremity, lower extremity, and trunk were similar in the groups. A significant difference was observed in the topography of the joint torque of the right upper and lower extremity and of the trunk between the boxers and the taekwondo athletes and judoists $(\mathrm{p}<0.01)$. The topography of the joint torque of the flexors and extensors of the right shoulder was significantly different between the boxers and the taekwondo athletes and judoists $(\mathrm{p}<0.01)$. Conclusions. In martial arts, the training undergone by the athletes and their participation in competitions can be expected to affect their strength. The joint torque was similar in the combat groups examined in this study. Judoists and taekwondo athletes did not differ in muscle topography. Boxers differed from the other two groups only in the contribution of the flexors and extensors of the right shoulder, in the sum of the torques of the right upper and lower limb, and the sum of the torques of the trunk. These results may be due to the characteristics of the discipline and the training methods used.
\end{abstract}

Key words: strength, muscle topography, judo, box, taekwondo

\section{Introduction}

Measurement of peak muscle torque is commonly used in sports diagnostics $[1,2,3]$. The most often used parameter is the maximal joint torque exerted by the groups of the flexors and extensors of the lower and upper extremities and the trunk in static position $[4,5,6,7,8]$. Muscle torque may be also expressed as a contribution of particular muscle groups to their sum $[7,9]$. Changes in maximal muscle torque may reflect the results of the training loads applied. Numerous reports have been published on the anthropology and physiology of combat sports athletes, but biomechanical investigations (involving physical characteristics) $[1,4,10]$ have been less frequent. Previously, a few comprehensive studies have examined the biomechanical characteristics of taekwondo athletes [3, 11, 12] and judoists $[2,4,10]$. There are no extensive studies on the biomechanical characteristics of boxers in the literature [1, 11, 13, 14]. The literature includes a small number of works comparing the results of the three combat sport groups examined in the current study (judoists, boxers, and taekwondo athletes).

The aim of the study was to explore differences in muscle strength and topography between judoists, boxers, and taekwondo athletes.

\section{Material and methods}

The study was granted approval by the Senate Research Ethics Committee of the Józef Piłsudski University of Physical Education in Warsaw. The subjects were informed about the scope and procedure of the study and of the possibility to withdraw from the study at any moment, and the study was conducted under the provisions of the Declaration of Helsinki. Thirteen judoists (including two members of the Polish national team), 6 boxers, and 7 taekwondo athletes (including one member of the Polish national team) took part in the study. Their mean ( \pm SD) age, body height, body mass, and training experience, respectively, were as follows: $15.7 \pm 0.9$ years, $173.2 \pm 9.6 \mathrm{~cm}$, $66.9 \pm 12.5 \mathrm{~kg}$, and $6.8 \pm 2.6$ years for the judoists; $16.8 \pm 1.0$ years, $185.7 \pm 6.0 \mathrm{~cm}, 75.8 \pm 7.1 \mathrm{~kg}$, and $2.1 \pm 1.2$ years for the boxers; and $17.8 \pm 0.7$ years, $179.5 \pm 4.1 \mathrm{~cm}, 63.6 \pm 6.4 \mathrm{~kg}$, and $6.4 \pm$ 1.5 years for the taekwondo athletes. No significant differences were found between the groups for body mass, but a significant difference was observed between the judoists and boxers for body height, between the boxers and the other two groups for training experience, and between the judoists and the other two groups for age.

The maximal joint torque of the flexors and extensors of the elbow, shoulder, hip, knee, and trunk were measured under isometric conditions using a special torque meter (Institute of Sport, Poland) type SMS1 (upper extremities) and SMS2 (lower extremities and trunk) [15]. The joint torques in the elbow flexors and extensors were measured in a sitting position. The subject's arm was supported on an armrest. The angle at the arm joint was $90^{\circ}$. The forearm was positioned at a right angle with respect to the arm. The measurements of the joint torque of the arm flexors and extensors were taken in a sitting position. The angle at the arm joint was $70^{\circ}$ during extension and $50^{\circ}$ during flexion. The trunk was in contact with the testing station, and 
it was stabilised by having an assistant press the subject's chest against the testing station. The joint torques in the knee flexors and extensors and trunk flexors and extensors were measured in sitting position. The angle in the hip and knee joints was $90^{\circ}$. The subjects were stabilised at the level of the anterior iliac spine and the distal part of the thigh using straps. The upper limbs were crossed on the subject's chest. The torque of the muscles which extended the limb in the hip joint was measured in a face-up position. The angle at the hip joint was $90^{\circ}$. The subject stabilised the trunk, holding the testing station with their hands. The maximal extension of the limb at the elbow, knee, and hip joints was adopted as $0^{\circ}$. In the arm joint, the position of the limb along the trunk was adopted as $0^{\circ}$. The position of the trunk in the face-up position was adopted as $0^{\circ}$. The rotation axis in the joint being measured corresponded with the rotation axis of the torque meter. Both the upper and lower limbs were measured separately for the left and right sides, maintaining the order flexion-extension. The subjects were instructed to develop a maximal value of torque. The topography of joint torque was calculated using the following formula (in the example below, the topography of the flexors of right shoulder, TFRS, was calculated):

Table 1. Mean values $( \pm \mathrm{SD})$ of the maximal joint torque $[\mathrm{N} \cdot \mathrm{m}]$ of the flexors (F) and extensors (E) of the left elbow, shoulder, hip, knee, and trunk

\begin{tabular}{|c|c|c|c|c|}
\hline Joints & & Boxers $(\mathrm{n}=\mathbf{6})$ & TKD $(\mathrm{n}=7)$ & Judoists $(\mathrm{n}=13)$ \\
\hline Elbow & $\mathrm{F}$ & $75.8 \pm 13.5$ & $60.3 \pm 13.8$ & $66.5 \pm 17.1$ \\
\hline & $\mathrm{E}$ & $50.0 \pm 9.4$ & $39.1 \pm 7.8$ & $46.8 \pm 13.5$ \\
\hline Shoulder & $\mathrm{F}$ & $57.8 \pm 9.3$ & $48.1 \pm 8.7$ & $50.3 \pm 13.7$ \\
\hline & $\mathrm{E}$ & $81.2 \pm 24.7$ & $63.9 \pm 13.0$ & $75.6 \pm 23.2$ \\
\hline Hip & $\mathrm{F}$ & $95.5 \pm 13.9$ & $97.9 \pm 16.8$ & $95.4 \pm 26.1$ \\
\hline & $\mathrm{E}$ & $431.5 \pm 176.1$ & $409.1 \pm 84.9$ & $439.7 \pm 129.1$ \\
\hline Knee & $\mathrm{F}$ & $129.5 \pm 33.8$ & $116.0 \pm 22.4$ & $118.8 \pm 26.5$ \\
\hline & $\mathrm{E}$ & $260.7 \pm 72.3$ & $241.1 \pm 43.9$ & $255.9 \pm 75.9$ \\
\hline Trunk & $\mathrm{F}$ & $185.7 \pm 18.7$ & $165.9 \pm 31.0$ & $164.2 \pm 52.7$ \\
\hline & $\mathrm{E}$ & $514.8 \pm 151.6$ & $406.0 \pm 92.9$ & $440.6 \pm 117.3$ \\
\hline
\end{tabular}

TKD = taekwondo athletes
TFRS Topography $=\frac{\text { joint torque of right shoulder flexors }}{\text { sum of joint torque of twenty muscle groups }} \cdot 100$.

All the measurements were made on one day, and each group was tested on a separate day in November.

\section{Warm-up}

Before the strength measurement, the subjects performed a 5-minute warm-up consisting of light exercise (running; arm, hip, and trunk circles; as well as squats followed by stretching exercises).

\section{Statistical analysis}

One-way ANOVA procedures with a post-hoc Scheffé test were employed to compare the mean values between groups. The effect size (ES) in ANOVA was assessed with eta squared and interpreted as follows: $0.01 \leq \eta^{2}<0.06$ - small effect size, $0.06 \leq \eta^{2}<0.14-$ medium effect size, and $\eta^{2} \geq 0.14$ - large effect size. The level of statistical significance was set at $\mathrm{p}<0.05$. Statistica v. 12.0 software (StatSoft, USA) was used in data analysis.

Table 2. Mean values $( \pm \mathrm{SD})$ of the maximal joint torque $[\mathrm{N} \cdot \mathrm{m}]$ of the flexors (F) and extensors (E) of the right elbow, shoulder, hip, and knee

\begin{tabular}{|c|c|c|c|c|}
\hline Joints & & Boxers $(\mathbf{n}=\mathbf{6})$ & TKD $(\mathbf{n}=\mathbf{7})$ & Judoists $(\mathbf{n}=13)$ \\
\hline Elbow & F & $78.0 \pm 14.6$ & $63.1 \pm 9.4$ & $68.8 \pm 18.2$ \\
\hline & E & $51.7 \pm 10.4$ & $38.7 \pm 8.3$ & $43.6 \pm 13.2$ \\
\hline Shoulder & F & $62.5 \pm 9.9$ & $42.1 \pm 10.3^{\mathrm{a}}$ & $49.2 \pm 10.4^{\mathrm{a}}$ \\
\hline & $\mathrm{E}$ & $80.8 \pm 23.3$ & $57.6 \pm 11.86$ & $63.9 \pm 17.42$ \\
\hline Hip & $\mathrm{F}$ & $98.7 \pm 13.5$ & $101.9 \pm 15.6$ & $97.2 \pm 31.8$ \\
\hline & $\mathrm{E}$ & $427.7 \pm 161.1$ & $411.0 \pm 79.0$ & $442.0 \pm 130.1$ \\
\hline Knee & $\mathrm{F}$ & $141.8 \pm 30.4$ & $124.7 \pm 35.9$ & $131.8 \pm 23.9$ \\
\hline & $\mathrm{E}$ & $264.8 \pm 74.5$ & $263.4 \pm 61.9$ & $274.2 \pm 54.2$ \\
\hline
\end{tabular}

TKD = taekwondo athletes; ${ }^{\mathrm{a}}=$ significantly different from the results recorded for the boxers; $\mathrm{p}<0.05$.

Table 3. Mean values $( \pm \mathrm{SD})$ of the relative maximal joint torque $\left[\mathrm{N} \cdot \mathrm{m} \cdot \mathrm{kg}^{-1}\right]$ of the flexors $(\mathrm{F})$ and extensors $(\mathrm{E})$ of the elbow, shoulder, hip, knee, and trunk

\begin{tabular}{|c|c|c|c|c|c|c|c|}
\hline & & $\begin{array}{c}\text { Boxers } \\
(\mathbf{n = 6})\end{array}$ & $\begin{array}{c}\text { TKD } \\
(\mathbf{n}=7)\end{array}$ & $\begin{array}{c}\text { Judoists } \\
(\mathbf{n}=13)\end{array}$ & $\begin{array}{c}\text { Boxers } \\
(\mathbf{n = 6})\end{array}$ & $\begin{array}{c}\text { TKD } \\
(\mathbf{n}=7)\end{array}$ \\
\hline Joints & & Left & Left & Left & Right & Right \\
\hline Elbow & $\mathrm{F}$ & $1.00 \pm 0.13$ & $0.94 \pm 0.16$ & $0.99 \pm 0.17$ & $1.03 \pm 0.14$ & $0.99 \pm 0.09$ & $1.02 \pm 0.13$ \\
\hline & $\mathrm{E}$ & $0.66 \pm 0.08$ & $0.61 \pm 0.09$ & $0.70 \pm 0.14$ & $0.68 \pm 0.09$ & $0.61 \pm 0.12$ & $0.65 \pm 0.15$ \\
\hline Shoulder & $\mathrm{F}$ & $0.76 \pm 0.10$ & $0.76 \pm 0.10$ & $0.75 \pm 0.15$ & $0.83 \pm 0.14$ & $0.65 \pm 0.10$ & $0.74 \pm 0.14$ \\
\hline & $\mathrm{E}$ & $1.07 \pm 0.29$ & $1.0 \pm 0.17$ & $1.13 \pm 0.30$ & $1.06 \pm .26$ & $0.90 \pm 0.14$ & $0.96 \pm 0.23$ \\
\hline Hip & $\mathrm{F}$ & $1.26 \pm 0.16$ & $1.54 \pm 0.19$ & $1.43 \pm 0.32$ & $1.30 \pm 0.15$ & $1.60 \pm 0.16$ & $1.44 \pm 0.35$ \\
\hline & $\mathrm{E}$ & $5.57 \pm 1.92$ & $6.38 \pm 0.73$ & $6.53 \pm 1.27$ & $5.54 \pm 1.70$ & $6.42 \pm 0.72$ & $6.58 \pm 1.34$ \\
\hline Knee & $\mathrm{F}$ & $1.73 \pm 0.52$ & $1.82 \pm 0.25$ & $1.78 \pm 0.24$ & $1.89 \pm 0.45$ & $1.94 \pm 0.42$ & $1.99 \pm 0.31$ \\
\hline & $\mathrm{E}$ & $3.42 \pm 0.77$ & $3.81 \pm 0.68$ & $3.87 \pm 1.04$ & $3.47 \pm 0.76$ & $4.14 \pm 0.83$ & $4.17 \pm 0.83$ \\
\hline Trunk & $\mathrm{F}$ & $2.45 \pm 0.17$ & $2.60 \pm 0.31$ & $2.43 \pm 0.55$ & & & \\
\hline & $\mathrm{E}$ & $6.74 \pm 1.60$ & $6.33 \pm 0.90$ & $6.58 \pm 1.24$ & & \\
\hline
\end{tabular}

TKD = taekwondo athletes. 
Table 4. Mean values $( \pm \mathrm{SD})$ of the sums of the relative maximal joint torque and topography of the maximal joint torque of the right $(\mathrm{R})$ and left $(\mathrm{L})$ upper extremity (SUE) and lower extremity (SLE) as well as the trunk (ST)

\begin{tabular}{|c|c|c|c|c|c|c|}
\hline \multirow[b]{2}{*}{ Variables } & \multicolumn{2}{|c|}{ Muscle torque $\left[\mathrm{N} \cdot \mathrm{m} \mathrm{kg}^{-1}\right]$} & \multirow[b]{2}{*}{$\begin{array}{l}\text { Judoists } \\
(n=13)\end{array}$} & \multicolumn{2}{|c|}{ Muscle topography [\%] } & \multirow[b]{2}{*}{ Judoists $(n=13)$} \\
\hline & $\begin{array}{l}\text { Boxers } \\
(n=6)\end{array}$ & $\begin{array}{c}\text { TKD } \\
(n=7)\end{array}$ & & $\begin{array}{l}\text { Boxers } \\
(n=6)\end{array}$ & $\begin{array}{c}\text { TKD } \\
(n=7)\end{array}$ & \\
\hline SUER & $3.59 \pm 0.50$ & $3.16 \pm 0.37$ & $3.38 \pm 0.59$ & $9.0 \pm 0.84$ & $7.3 \pm 0.74^{a}$ & $7.7 \pm 0.91^{a}$ \\
\hline SUEL & $3.49 \pm 0.51$ & $3.31 \pm 0.39$ & $3.58 \pm 0.68$ & $8.7 \pm 0.9$ & $7.7 \pm 0.8$ & $8.2 \pm 1.0$ \\
\hline SLER & $12.20 \pm 2.55$ & $14.11 \pm 1.35$ & $14.18 \pm 1.62$ & $30.1 \pm 1.4$ & $32.8 \pm 1.2^{\mathrm{a}}$ & $32.5 \pm 1.3^{a}$ \\
\hline SLEL & $11.98 \pm 2.52$ & $13.54 \pm 0.98$ & $13.61 \pm 2.21$ & $29.5 \pm 1.8$ & $31.5 \pm 1.0$ & $31.1 \pm 2.0$ \\
\hline ST & $9.19 \pm 1.67$ & $8.93 \pm 1.05$ & $9.01 \pm 1.62$ & $22.8 \pm 1.4$ & $20.7 \pm 1.4^{a}$ & $20.5 \pm 1.7^{a}$ \\
\hline
\end{tabular}

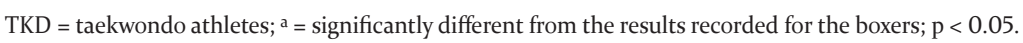

Table 5. Mean values ( \pm SD) of the topography [\%] of the maximal joint torque of the flexors $(F)$ and extensors (E) of the elbow, shoulder, hip, knee, and trunk

\begin{tabular}{|c|c|c|c|c|c|c|c|}
\hline & & $\begin{array}{c}\text { Boxers } \\
(\mathbf{n}=\mathbf{6})\end{array}$ & $\begin{array}{c}\text { TKD } \\
(\mathbf{n}=7)\end{array}$ & $\begin{array}{c}\text { Judoists } \\
(\mathbf{n}=13)\end{array}$ & $\begin{array}{c}\text { Boxers } \\
(\mathbf{n}=\mathbf{6})\end{array}$ & $\begin{array}{c}\text { TKD } \\
(\mathbf{n}=7)\end{array}$ \\
\hline Joints & & Left & Left & Left & Right & Right & Right \\
\hline Elbow & F & $2.5 \pm 0.4$ & $2.2 \pm 0.3$ & $2.3 \pm 0.2$ & $2.6 \pm 0.3$ & $2.3 \pm 0.2$ & $2.3 \pm 0.2$ \\
\hline & E & $1.6 \pm 0.2$ & $1.4 \pm 0.2$ & $1.6 \pm 0.3$ & $1.7 \pm 0.2$ & $1.4 \pm 0.3$ & $1.5 \pm 0.3$ \\
\hline Shoulder & F & $1.9 \pm 0.3$ & $1.8 \pm 0.3$ & $1.7 \pm 0.2$ & $2.1 \pm 0.4$ & $1.5 \pm 0.2^{\mathrm{a}}$ & $1.7 \pm 0.2^{\mathrm{a}}$ \\
\hline & $\mathrm{E}$ & $2.6 \pm 0.4$ & $2.3 \pm 0.4$ & $2.6 \pm 0.5$ & $2.6 \pm 0.4$ & $2.1 \pm 0.3^{\mathrm{a}}$ & $2.2 \pm 0.4^{\mathrm{a}}$ \\
\hline Hip & $\mathrm{F}$ & $3.2 \pm 0.7$ & $3.6 \pm 0.4$ & $3.2 \pm 0.5$ & $3.3 \pm 0.5$ & $3.7 \pm 0.4$ & $3.3 \pm 0.6$ \\
\hline & $\mathrm{E}$ & $13.5 \pm 3.0$ & $14.8 \pm 1.0$ & $14.9 \pm 1.8$ & $13.5 \pm 2.2$ & $14.9 \pm 0.9$ & $15.0 \pm 2.4$ \\
\hline Knee & F & $4.3 \pm 1.3$ & $4.3 \pm 0.7$ & $4.1 \pm 0.7$ & $4.7 \pm 1.1$ & $4.5 \pm 0.9$ & $4.6 \pm 0.8$ \\
\hline & $\mathrm{E}$ & $8.5 \pm 1.2$ & $8.9 \pm 1.5$ & $8.8 \pm 1.7$ & $8.6 \pm 1.0$ & $9.6 \pm 1.6$ & $9.6 \pm 1.7$ \\
\hline Trunk & F & $6.2 \pm 1.1$ & $6.1 \pm 0.8$ & $5.5 \pm 0.8$ & & & \\
\hline & E & $16.6 \pm 1.1$ & $14.7 \pm 1.2$ & $15.0 \pm 1.6$ & & & \\
\hline
\end{tabular}

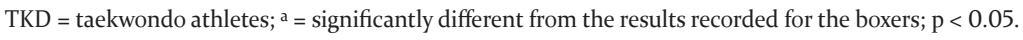

\section{Results}

Mean $( \pm S D)$ values of the joint torque are presented in tables 1-3. The absolute and relative joint torque was similar in the three groups with the exception of the absolute strength of the right flexor of the shoulder $\left(F_{2,23}=6.514, p=0.006, \eta^{2}=0.362\right)$ (tab. 2). The sums of the relative maximal joint torque and topography of the maximal joint torque of the right (R) and left (L) upper extremity (SUE) and lower extremity (SLE) as well as the trunk (ST) were similar in the groups as well (tab. 4). A significant difference was observed between the topography of the maximal joint torque of the right upper extremity $\left(F_{2,23}=6.376\right.$, $\left.\mathrm{p}=0.006, \eta^{2}=0.357\right)$, right lower extremity $\left(\mathrm{F}_{2,23}=8.540, \mathrm{p}=\right.$ $\left.0.002, \eta^{2}=0.426\right)$, and trunk $\left(F_{2,23}=4.350, p=0.030, \eta^{2}=\right.$ $0.275)$ between the boxers and the taekwondo athletes and judoists (tab. 4).

There was also a significant difference between the topography of the maximal joint torque of the flexors $\left(\mathrm{F}_{2,23}=7.809, \mathrm{p}=\right.$ $\left.0.003, \eta^{2}=0.404\right)$ and extensors $\left(F_{2,23}=4.343, p=0.025, \eta^{2}=\right.$ 0.274 ) of the right shoulder for the boxers and the taekwondo athletes and judoists (tab. 5).

\section{Discussion}

Success in combat sports requires a high level of physical preparation $[16,17,18]$. The planning of training should focus on the athletes' physical abilities, including muscle strength.
Changes in maximal joint torque are indicative of the athlete's training level and the effects of the training loads applied. The study analysed peak joint torques developed under isometric conditions. The main findings of the present study were that maximal strength did not significantly differ between judoists, boxers, and taekwondo athletes.

An evaluation of the strength of the lower limbs of female and male judo contestants from the Polish national team was performed by Buśko and Nowak [10]. In comparison to the Polish senior judo national team, the relative results of the maximal muscle strength of contestants from the judo group (examined for the purposes of this study) were considerably lower. The sum of the peak muscle torques for 10 muscle groups studied in the boxers was 3,088.5 $\pm 760.7 \mathrm{~N} \cdot \mathrm{m}$ and was much greater than that in the study published by Janiak and Krawczyk [1], where it was 2,439 $\pm 549 \mathrm{~N} \cdot \mathrm{m}$. In a study by Pędzich et al. [3], taekwondo WTF athletes developed the following joint torques for the flexors and extensors, respectively, in static conditions: in the rear upper limb $-1.1 \pm 0.1 \mathrm{~N} \cdot \mathrm{m} / \mathrm{kg}$ and $0.71 \pm 0.1 \mathrm{~N} \cdot \mathrm{m} / \mathrm{kg}$ at the elbow joint and $1.48 \pm 0.3 \mathrm{~N} \cdot \mathrm{m} / \mathrm{kg}$ and $1.42 \pm 0.3 \mathrm{~N} \cdot \mathrm{m} / \mathrm{kg}$ at the shoulder joint; in the lower limb $-2.12 \pm 0.3 \mathrm{~N} \cdot \mathrm{m} / \mathrm{kg}$ and $3.62 \pm 0.7 \mathrm{~N} \cdot \mathrm{m} / \mathrm{kg}$ at the knee joint and $2.81 \pm 0.4 \mathrm{~N} \cdot \mathrm{m} / \mathrm{kg}$ and $6.37 \pm 0.7 \mathrm{~N} \cdot \mathrm{m} / \mathrm{kg}$ at the hip joint; and, finally, in the trunk: $3.94 \pm 0.6 \mathrm{~N} \cdot \mathrm{m} / \mathrm{kg}$ and $7.09 \pm 0.4 \mathrm{~N} \cdot \mathrm{m} / \mathrm{kg}$. The values of joint torques in our taekwondo athletes were not significantly lower than the results obtained by the athletes in the study by Pędzich et al. [3]. This is likely to have been caused by the use of different 
measurement positions and performing the measurements on different testing stations.

Numerous studies have been devoted to the measurement of muscle strength or muscle torque which has been frequently presented as the percent contribution of particular muscle groups [7, 19, 20]. Fidelus and Skorupski [20] suggested that in athletes there are specific sport-related topographies of joint torques. In the present study, the topography of the maximal joint torques did not significantly differ in the three groups except for the contribution of the flexors and extensors of the right shoulder, the sum of the torques of the right upper and lower limbs, and the sum of the torques of the trunk, which differed between the boxers and the judoists and taekwondo athletes. The demonstrated changes in the joint torques and topography of the torques may suggest that the training loads applied may have been similar and the differences in topography between the combat groups arise from the specificity of the disciplines (the technical elements: punches, kicks, and throws).

\section{Conclusions}

In martial arts, the training undergone by the athletes and their participation in competitions can be expected to affect their strength. It is not always training with maximal, external load that produces maximal strength, because increases in force may in large part be neurologically based [21]. Hence, the joint torque was similar in the combat groups examined in the study. Judoists and taekwondo athletes did not differ in muscle topography. Boxers differed from both other groups only in the contribution of the flexors and extensors of the right shoulder as well as in the sum of the torques of the right upper and lower limbs and the sum of the torques of the trunk. These results may be due to the characteristics of the discipline and the training methods used. Torque measurement provides additional information that is useful for planning, monitoring, and optimising training.

\section{Acknowledgements}

The study was supported by the Polish Ministry of Science and Higher Education, under Grant No. DS. 134 received by the Józef Piłsudski University of Physical Education in Warsaw.

\section{Literature}

1. Janiak J., Krawczyk B. (1995). Relationships between muscle force and total or lean body mass in highly experienced combat athletes. Biology of Sport 12(2), 107-111.

2. Lewandowska J., Buśko K., Pastuszak A., Boguszewska K. (2011). Somatotype variables related to muscle torque and power in judoists. Journal of Human Kinetics 30, 512.

3. Pędzich W., Mastalerz A., Sadowski J. (2012). Estimation of muscle torque in various combat sports. Acta of Bioengineering and Biomechanics 14(4), 107-112.

4. Boguszewska K., Boguszewski D., Buśko K. (2010). Special Judo Fitness Test and biomechanics measurements as a way to control of physical fitness in young judoists. Archives of Budo 6(4), 205-209.

5. Buśko K. (1989). Selected biomechanical characteristics of male and female basketball national team players. Biology of Sport 4, 319-329.
6. Buśko K., Gajewski J., Mazur J., Michalski R., Łach P. (2013). Strength profile in young male athletes from different sports. Biomedical Human Kinetics 5, 77-83. DOI: 10.2478/ bhk-2013-0012.

7. Janiak J., Wit A., Stupnicki R. (1993). Static muscle force in athletes practising rowing. Biology of Sport 10, 29-34.

8. Szpala A., Rutkowska-Kucharska A., Drapała J., Brzostowski K. (2011). Choosing the right body position for assessing trunk flexors and extensors torque output. $\mathrm{Hu}$ man Movement 12(1), 57-64.

9. Buśko K. (1998). Muscle torque topography of female basketball players. Biology of Sport 15(1), 45-49.

10. Buśko K., Nowak A. (2008). Changes of maximal muscle torque and maximal power output of lower extremities in male judoists during training. Human Movement 9(2), 111115.

11. Karpiłowski B., Nosarzewski Z., Staniaki Z., Trzaskoma Z. (2001). Dependence between the impact force and the static moment of force of some chosen muscle units in boxing. Acta of Bioengineering and Biomechanics 3(Suppl. 2), 241244. [in Polish, English abstract]

12. Pędzich W., Mastalerz A., Urbanik C. (2006). The comparison of the dynamics of selected leg strokes in taekwondo WTF. Acta of Bioengineering and Biomechanics 8(1), 83-90.

13. Danai G., Nikolaidis P.T. (2012). Differences in force-velocity characteristics of upper and lower limbs of non-competitive male boxers. International Journal of Exercise Science 5(2), 106-113.

14. Smith M.S., Dyson R.J., Hale T., Janaway L. (2000). Development of a boxing dynamometer and its punch force discrimination efficacy. Journal of Sports Sciences 18(6), 445450.

15. Buśko K., Lewandowska J., Lipińska M., Michalski R., Pastuszak A. (2013). Somatotype variables related to muscle torque and power output in female volleyball players. Acta of Bioengineering and Biomechanics 15(2), 119-126.

16. Franchini E., Takito M.Y., Kiss M.A.P.D.M., Sterkowicz S. (2005). Physical fitness and anthropometrical differences between elite and non-elite judo players. Biology of Sport 22, 315-328.

17. Francini E., Huertas J.R., Sterkowicz S., Carratala V., Gutiérrez-García C., Escobar-Molina R. (2011). Anthropometrical profile of elite Spanish judoka: Comparative analysis among ages. Archives of Budo 7(4), 239-245.

18. Ji-Woong N., Ju-Hyun K., Junghwan K. (2014). Somatotype analysis of elite judo athletes compared with nonathletes for health science research. Toxicology and Environmental Health Sciences 6(2), 99-105.

19. Buśko K. (2012). Training-induced changes in the topography of muscle torques and maximal muscle torques in basketball players. Biology of Sport 29(1), 77-83.

20. Fidelus K., Skorupski L. (1970). The levels of muscle torques in joints of athletes from various sports. In Workshop on Sport Technique Theory (pp. 128-140), 26-28 November 1968, Warsaw. [in Polish]

21. Rutherford O.M., Jones D.A. (1986). The role of learning and co-ordination in strength training. European Journal of Applied Physiology 55, 100-105.

Submitted: October 27, 2016

Accepted: November 3, 2016 